\section{(6) OPEN ACCESS}

\title{
Effect of CPAP on blood pressure in patients with minimally symptomatic obstructive sleep apnoea: a meta-analysis using individual patient data from four randomised controlled trials
}

\author{
Daniel J Bratton, ${ }^{1}$ John R Stradling, ${ }^{2}$ Ferran Barbé, ${ }^{3}$ Malcolm Kohler ${ }^{4}$
}

- Additional material is published online only. To view please visit the journal online (http://dx.doi.org/10.1136/ thoraxjnl-2013-204993).

${ }^{1}$ Medical Research Council Clinical Trials Unit at University College London, London, UK ${ }^{2}$ Oxford Centre for Respiratory Medicine and NIHR Biomedical Research Centre, Oxford University, Oxford, UK ${ }^{3}$ Department of Pneumology, Biomedical Research Institute IRB Lleida and CIBERES, Madrid, Spain

${ }^{4}$ Division of Pulmonology, University Hospital Zurich, Zurich, Switzerland

\section{Correspondence to} Daniel J Bratton, Medical Research Council Clinical Trials Unit, 125 Kingsway, London, WC2B 6NH, UK; daniel.bratton@ucl.ac.uk

Received 18 December 2013 Revised 23 April 2014 Accepted 25 May 2014 Published Online First 19 June 2014

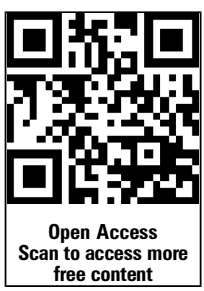

\section{SLinked}

- http://dx.doi.org/10.1136/ thoraxjnl-2014-205430

\section{CrossMark}

To cite: Bratton DJ,

Stradling JR, Barbé $F$, et al. Thorax 2014;69:

1128-1135.

\section{ABSTRACT}

Background CPAP reduces blood pressure (BP) in patients with symptomatic obstructive sleep apnoea (OSA). Whether the same benefit is present in patients with minimally symptomatic OSA is unclear, thus a meta-analysis of existing trial data is required.

Methods The electronic databases Medline, Embase and trial registries were searched. Trials were eligible if they included patients with minimally symptomatic OSA, had randomised them to receive CPAP or either shamCPAP or no CPAP, and recorded BP at baseline and follow-up. Individual participant data were obtained. Primary outcomes were absolute change in systolic and diastolic BP.

Findings Five eligible trials were found (1219 patients) from which data from four studies (1206 patients) were obtained. Mean (SD) baseline systolic and diastolic BP across all four studies was 131.2 (15.8) $\mathrm{mm} \mathrm{Hg}$ and 80.9 (10.4) mm Hg, respectively. There was a slight increase in systolic BP of $1.1 \mathrm{~mm} \mathrm{Hg}(95 \% \mathrm{Cl}-0.2$ to 2.3, $\mathrm{p}=0.086$ ) and a slight reduction in diastolic BP of $0.8 \mathrm{~mm} \mathrm{Hg}(95 \% \mathrm{Cl}-1.6$ to $0.1, p=0.083)$, although the results were not statistically significant. There was some evidence of an increase in systolic BP in patients using CPAP $<4 \mathrm{~h} /$ night $(1.5 \mathrm{~mm} \mathrm{Hg}, 95 \% \mathrm{Cl}-0.0$ to 3.1, $p=0.052)$ and reduction in diastolic $B P$ in patients using CPAP $>4 \mathrm{~h} /$ night $(-1.4 \mathrm{~mm} \mathrm{Hg}, 95 \% \mathrm{Cl}-2.5$ to $-0.4, p=0.008)$. CPAP treatment reduced both subjective sleepiness $(p<0.001)$ and OSA severity $(p<0.001)$.

Interpretation Although CPAP treatment reduces OSA severity and sleepiness, it seems not to have a beneficial effect on BP in patients with minimally symptomatic OSA, except in patients who used CPAP for $>4 \mathrm{~h} /$ night.

\section{INTRODUCTION}

Obstructive sleep apnoea (OSA) is characterised by repetitive apnoea and hypopnoea during sleep, associated with oxygen desaturations and arousals from sleep. It has been estimated that between 2 and $4 \%$ of the adult population in Western countries suffer from symptomatic OSA (OSAS), and it is becoming more prevalent as the average population body weight rises. ${ }^{1}$ The prevalence of minimally symptomatic OSA presenting without overt daytime sleepiness among middle-aged adults has been shown to be as high as $30 \%,{ }^{1}$ making OSA a frequent disorder, and thus of major epidemiological interest.

\section{Key messages}

What is the key question?

- Can CPAP reduce blood pressure in patients with minimally symptomatic sleep apnoea?

What is the bottom line?

- Although there is no overall improvement in blood pressure, we found that optimal CPAP usage can result in a decrease in diastolic blood pressure.

\section{Why read on?}

- We use a novel method for meta-analysis of interactions between treatment effects and continuous covariates, which is more powerful than existing methods and shows interactions in much more detail.

OSAS has been proven to be a causal factor in the pathogenesis of vascular dysfunction and hypertension. ${ }^{2}$ Treatment of OSAS patients with CPAP has been shown to reduce blood pressure (BP) by approximately $2-10 \mathrm{~mm} \mathrm{Hg}$ in several randomised controlled trials (RCTs). ${ }^{3-6}$ Furthermore, in patients with resistant hypertension and OSA, CPAP achieves reductions in $24 \mathrm{~h}$ BP of about 5-10 mm Hg. ${ }^{7} 8$

Whether CPAP has the same beneficial effect on $\mathrm{BP}$ in patients with minimally symptomatic OSA is a matter of debate and, because of the high prevalence of the disorder, this question is of considerable clinical interest. The findings from five $\mathrm{RCTs}^{9-13}$ have been controversial and suggest that perhaps only specific subgroups of minimally symptomatic OSA patients (eg, patients with optimal adherence to CPAP and those with hypertension) may benefit from CPAP in terms of BP reduction. However, as only a limited number of such patients have been included in the individual trials, we performed a meta-analysis using individual patient data from all participants in the existing RCTs in order to explore this clinically and epidemiologically important question. We also use a novel method for analysing treatment-effect interactions with continuous covariates using fractional polynomials, ${ }^{14}$ which is more powerful than conventional methods and allows 
more accurate inference to be drawn on which groups of patients may benefit most from treatment.

\section{METHODS}

The meta-analysis followed a prespecified protocol and statistical analysis plan that outlined the objectives, outcomes, methods for identifying trials and methods of analysis.

\section{Inclusion criteria}

Trials must have been randomised, closed to patient accrual, included patients with a diagnosis of minimally symptomatic or asymptomatic OSA and randomised patients to receive CPAP, or either sham-CPAP or no CPAP (standard care). Trials must also have measured systolic (SBP) and diastolic BP (DBP) on each patient at enrolment and at a follow-up visit.

\section{Identification of trials}

To limit publication bias, both published and unpublished studies were eligible for inclusion. A literature search was performed in March 2013 of Medline, Embase and the Cochrane Central Register of Controlled Trials (Central) using the Cochrane Collaboration Highly Sensitive Search Strategy for identifying RCTs (sensitivity-maximising and precision-maximising version). ${ }^{15}$ The full electronic search strategy for Medline is shown in the online supplement. Reference lists of all identified trials and review articles were also screened for relevant trials. Clinical trials registries were searched for unpublished trials.

\section{Data collection}

Prior to data collection, a list of the required and desired variables for analysis was included in the protocol. SBP and DBP measurements from baseline and all follow-up visits were required along with treatment allocation, date of randomisation and anonymous patient identifier. Daytime or office BP readings were desirable. Baseline and follow-up data on Epworth Sleepiness Score (ESS) and oxygen desaturation index (ODI) (or apnoea-hypopnoea index (AHI) if ODI was unavailable) were desirable, along with age or date of birth, gender, body mass index (BMI) and antihypertensive medication usage. Although not identical, ODI and AHI are relatively similar and for pragmatic reasons were assumed to be the same. CPAP treatment usage (mean number of hours used per night of follow-up) was collected for patients randomised to CPAP. All data were consistently coded between studies before performing the meta-analysis.

\section{Risk of bias assessment}

All data were checked for completeness, validity and consistency. Data queries were resolved with the relevant trial team. Standard checks such as patterns of treatment allocation and balance of baseline characteristics between treatment arms were used to assess the integrity of the randomisation process in each study. Anonymous baseline and outcome data were sought for all randomised patients, regardless of whether they were excluded from the analysis of their respective trial.

\section{Endpoints}

The primary outcomes were absolute change in SBP and DBP between baseline and follow-up. Secondary outcomes were change in ESS and change in ODI. All outcomes were analysed using data from the 6-month visit or the nearest available visit. Only data from the first period of treatment were used from crossover trials.

The effect of CPAP usage ( $<$ or $>4 \mathrm{~h} /$ night) on each outcome, compared with control, was investigated.
Furthermore, the variation in the effect of CPAP on BP and ESS was explored over baseline ESS, ODI/AHI, gender, BMI and, for BP outcomes only, baseline BP and antihypertensive medication usage.

\section{Statistical analysis}

Outcomes were analysed on an intention-to-treat basis in each study using multiple linear regression models adjusting for treatment allocation, the corresponding baseline variable of the outcome, age, BMI, gender, ODI (or AHI) and antihypertensive medication usage (BP outcomes only). The adjusted treatment effects for each outcome (adjusted absolute difference in means) were then combined across trials using a fixed-effect inverse-variance-weighted meta-analysis. Treatment effects and 95\% CIs for each study and overall were presented using forest plots. Analyses were performed using Stata V.12. Heterogeneity was assessed using the $\mathrm{I}^{2}$-statistic ${ }^{16}$ and Cochran's $\chi^{2}$ test. $^{17}$ Regardless of the amount of heterogeneity present, random effects meta-analyses were not performed due to the small number of studies, thus making it difficult to precisely estimate the betweentrial variation. ${ }^{18}$

To estimate the effect of CPAP usage on each outcome, patients allocated to CPAP were dichotomised into those who used treatment for $<$ or $>4 \mathrm{~h} /$ night, which may be considered the minimum usage required for improved cardiovascular outcomes. $^{9} 19$ The adjusted treatment effect in each usage group was estimated relative to the controls and pooled across studies using a fixed-effects meta-analysis.

Treatment interactions with binary covariates (eg, gender), that is, the difference in the treatment effect between each subgroup (eg, males and females), were estimated for each study using a multiple linear regression model before pooling the coefficients for the interaction terms across studies using a fixed-effects inverse-variance-weighted meta-analysis.

The effect of CPAP relative to control at different levels of a continuous covariate (eg, age) was analysed using two approaches: (1) by splitting the continuous covariate at quartiles (determined on the pooled dataset) and pooling the estimated treatment effect in each resulting subgroup across studies and (2) by using fractional polynomials ${ }^{14}$ to produce a single, continuous function of the treatment effect over the covariate.

For method (2), an approach used by Sauerbrei and Royston ${ }^{20}$ for meta-analysis of continuous covariates in observational studies was adapted. We first estimated the best-fitting fractional polynomial function (with a single transformation of the covariate of interest) on the pooled dataset (stratified by study) adjusting for the same variables as used in the main analysis of the outcome of interest. A study-wise approach, whereby the best function is found for each study, was not used since two of the four studies we investigated had a relatively small sample size and would therefore have lacked power to find any nonlinear relationship. ${ }^{20}$ A regression model that included an interaction term between treatment and the transformed covariate was then fitted to each study. The coefficients for this interaction term and the treatment variable were then pooled across studies using a multivariate meta-analysis $^{21}$ to produce a single treatment effect curve with $95 \%$ CI and a $\mathrm{p}$ value to test for the presence of an interaction.

The results of both methods were included on the same plot to check the consistency between the two methods of analysis. Agreement between the results increases the plausibility and evidence of any possible treatment-covariate interaction. Disagreement may indicate a type I error of method (2) caused by the flexible modelling or an erroneous model, in which case 
the results of the subgroup analysis (method (1)) were interpreted.

\section{RESULTS}

A total of five eligible trials were found in the study searches (1219 patients in total, see figure 1). Data were available from four trials ${ }^{9} 101213$ that randomised 599 patients to CPAP and 607 to control (1206 patients). Data were unavailable for a pilot study of 13 patients ${ }^{11}$ and was excluded from the meta-analysis. Data for $99 \%$ of all known randomised patients were therefore included in the meta-analysis. Details of each of the four studies are shown in table 1 and baseline characteristics are summarised in table 2. Data checks showed that all studies used adequate methods of randomisation (data not shown).

The two largest studies ${ }^{9} 12$ compared CPAP against no CPAP and followed up patients at 6 months. The two smaller studies $^{10} 13$ used sham-CPAP as the control arm and used shorter follow-up periods. The study by Robinson $e$ t $a l^{13}$ was a crossover trial and so only data from the first period were used. Data for all primary and secondary outcomes were available from each study apart from the study by Barbé et al, ${ }^{9}$ which did not record AHI during follow-up. All baseline variables that were planned to be adjusted for were available.

Most studies regarded patients with an ESS $\leq 10$ to be nonsleepy, apart from the study by Craig et al, ${ }^{9}$ which used a pragmatic approach of allowing the clinician to decide whether a patient was minimally symptomatic at presentation. Despite this difference, there was only a small difference in average baseline
ESS scores between studies (table 2). Both studies by Barbé et $a l^{9}{ }^{10}$ measured OSA severity using AHI rather than ODI, and table 2 shows that mean AHI in these two studies was higher than mean ODI in the other studies.

\section{Primary analyses}

Complete data from 1074 and 1075 patients were available for the analyses of SBP and DBP, respectively. Figure 2 shows that there was a small increase in SBP of $1.1 \mathrm{~mm} \mathrm{Hg}(95 \% \mathrm{CI}-0.2$ to $2.3 \mathrm{~mm} \mathrm{Hg}$ ) and a decrease in DBP of $-0.8 \mathrm{~mm} \mathrm{Hg}(95 \% \mathrm{CI}$ -1.6 to 0.1 ) in patients on CPAP, relative to control, although these differences were not statistically significant $(p=0.086$ and 0.083 , respectively).

\section{Secondary analyses}

A total of 1096 and 446 complete cases were available for the analyses of ESS and ODI, respectively. Figure 3 shows that CPAP was estimated to improve subjective sleepiness by 1.1 points in the ESS scale compared with control $(95 \% \mathrm{CI}-1.5$ to $-0.8, \mathrm{p}<0.001)$. There was a large amount of heterogeneity caused by the stronger result of the Craig et $a l^{12}$ trial. Removing this study led to a conservative estimate of the treatment effect of $-0.6(95 \% \mathrm{CI}-1.1$ to $-0.2, \mathrm{p}=0.004)$.

Figure 3 shows that there was a strong, statistically significant effect of CPAP on ODI, reducing it by 8.2 events/h compared with control $(95 \%$ CI -10.1 to $-6.4, \mathrm{p}<0.001)$. The large amount of heterogeneity was driven by the result of Barbé et $a l,{ }^{10}$ which carried only $3.2 \%$ of the weight and so excluding

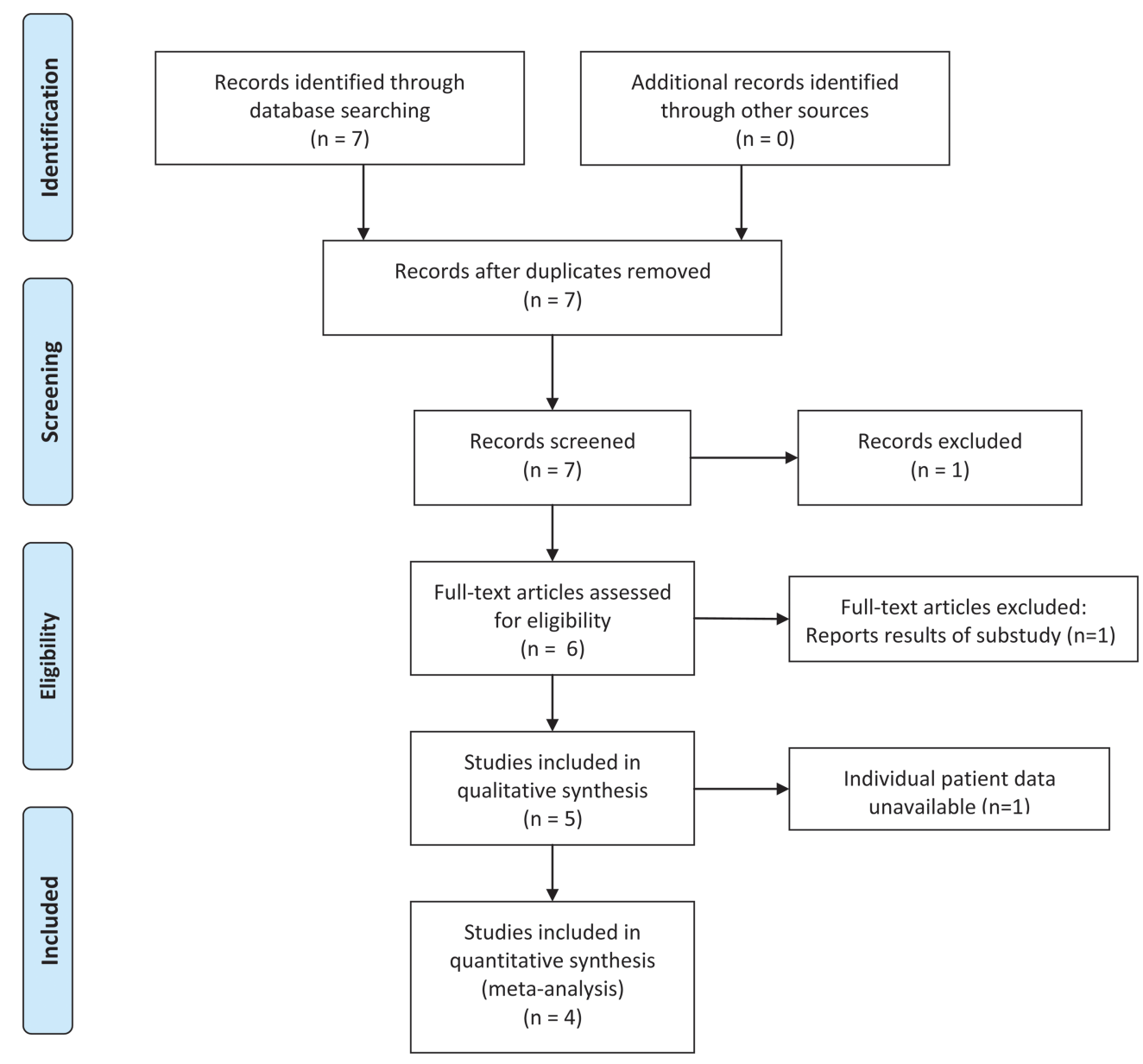

Figure 1 PRISMA flow diagram. 
Table 1 Summary of eligible trials

\begin{tabular}{|c|c|c|c|c|c|c|c|c|}
\hline \multirow[b]{2}{*}{ Trial } & \multirow[b]{2}{*}{ Location } & \multirow{2}{*}{$\begin{array}{l}\text { Accrual } \\
\text { period }\end{array}$} & \multirow[b]{2}{*}{ Inclusion criteria } & \multicolumn{2}{|c|}{ Intervention } & \multirow{2}{*}{$\begin{array}{l}\text { No. of patients } \\
\text { randomised }\end{array}$} & \multirow{2}{*}{$\begin{array}{l}\text { Length of } \\
\text { follow-up }\end{array}$} & \multirow{2}{*}{$\begin{array}{l}\text { BP readings } \\
\text { used }\end{array}$} \\
\hline & & & & Active & Control & & & \\
\hline Barbé et $a l^{10}$ & Spain & 1999-2000 & $\begin{array}{l}\mathrm{AHI} \geq 30 \\
\mathrm{ESS} \leq 10\end{array}$ & CPAP & Sham-CPAP & 55 & 6 weeks & Office \\
\hline Robinson et $a l^{13}$ & Oxford, UK & $2002-2004$ & $\begin{array}{l}\text { ODI }>10 \\
\text { ESS }<10 \\
\text { Hypertensive }\end{array}$ & $\begin{array}{l}\text { Therapeutic } \\
\text { CPAP }\end{array}$ & Sham-CPAP & 35 & 1 month & Daytime \\
\hline Barbé et $a l^{9}$ & Spain & 2004-2006 & $\begin{array}{l}\text { Age }>18 \text { and }<70 \\
A H I \geq 20 \\
E S S \leq 10\end{array}$ & CPAP & $\begin{array}{l}\text { 'Conservative' (Standard } \\
\text { care) }\end{array}$ & 725 & Median 4 years & Office \\
\hline Craig et $a l^{12}$ & $\begin{array}{l}\text { UK and } \\
\text { Canada }\end{array}$ & 2006-2009 & $\begin{array}{l}\text { ODI }>7.5 \\
\text { Minimally } \\
\text { symptomatic }\end{array}$ & CPAP & Standard care & 391 & 6 months & Daytime \\
\hline Total & & & & & & 1206 & & \\
\hline
\end{tabular}

AHI, apnoea-hypopnoea index; ODI, oxygen desaturation index; ESS, Epworth Sleepiness Score; BP, blood pressure.

it had little impact on the overall result (treatment effect= -7.4 events/h, $\mathrm{p}<0.001$ ).

\section{Effect of CPAP usage on outcomes}

A total of 541/599 (90\%) patients allocated to receive CPAP had usage data at follow-up. The median usage was $4.7 \mathrm{~h} /$ night and $54 \%$ of patients used treatment $>4 \mathrm{~h} /$ night on average (see online supplementary eTable S2.1)

Figure 4 shows that the increase in SBP in patients using CPAP $<4 \mathrm{~h} /$ night $(1.5 \mathrm{~mm} \mathrm{Hg}$ increase, $\mathrm{p}=0.052)$ is slightly higher than the overall effect, while there is a smaller effect in patients with higher usage $(0.6 \mathrm{~mm} \mathrm{Hg}$ decrease, $\mathrm{p}=0.49)$. However, the difference between these effects was not statistically significant $(p=0.41)$.

Figure 5 shows that there was a reduction in DBP relative to controls of $1.4 \mathrm{~mm} \mathrm{Hg}$ in patients with optimal CPAP usage $(p=0.008)$ while there was no change in patients using CPAP $<4 \mathrm{~h} /$ night $(\mathrm{p}=0.79)$. There was some evidence of a difference between these effects $(p=0.062)$.

Online supplementary figures S3.1 and S3.2 show that, while there were improvements in ESS and OSA severity in both usage groups compared with control, the benefits were greater in patients who used the treatment $>4 \mathrm{~h} /$ night on average.

\section{Treatment interactions}

There was no evidence of a treatment interaction with gender or antihypertensive medication use (see online supplementary figures S4.1-S4.5). Most of the interactions between continuous covariates and treatment effect on BP were not statistically significant (online supplement) apart from where there was marginal evidence that the effect of CPAP on DBP becomes more favourable as BMI increases $(p=0.052$; see online supplementary figure $\mathrm{S} 6$ ).

There were statistically significant interactions between the effect of CPAP on ESS and baseline ESS and ODI. The reduction in ESS was stronger in patients with a higher ESS score at baseline ( $\mathrm{p}=0.030$; figure 6) while there was strong evidence that the effect on ESS diminishes in patients with higher ODI $(p=0.014$; figure 7). Visual comparison of the continuous curves with the effects in quartiles by study and overall showed that in all analyses the two methods of analysis agreed quite well, thus increasing the plausibility of the findings.

\section{DISCUSSION}

The findings of this meta-analysis show that although CPAP reduces OSA severity and subjective sleepiness it seems not to have an overall beneficial effect on BP in patients with

Table 2 Baseline characteristics of each study and overall

\begin{tabular}{|c|c|c|c|c|c|}
\hline & Barbé et $a l^{10}$ & Robinson et al ${ }^{13}$ & Barbé et $a l^{9}$ & Craig et $a l^{12}$ & Total \\
\hline Sample size & 54 & 33 & 724 & 391 & 1202 \\
\hline Age (years) & $52.9(9.8)$ & $54.3(8.9)$ & $51.4(10.9)$ & $57.7(7.4)$ & $53.6(10.2)$ \\
\hline Gender (male) & $49(91 \%)$ & $29(88 \%)$ & $620(86 \%)$ & $305(78 \%)$ & $1003(83 \%)$ \\
\hline ESS & $7.4(2.1)$ & $5.9(2.6)$ & $6.5(2.3)$ & $8.0(4.3)$ & $7.0(3.1)$ \\
\hline ODI & - & $27.5(18-37.6)$ & - & $9.8(4.9-16.2)$ & $10.6(5.4-19.1)$ \\
\hline $\mathrm{AHI}$ & $53.6(40.5-70)$ & - & $37(27-55)$ & - & $38(28-56)$ \\
\hline $\mathrm{SBP}(\mathrm{mm} \mathrm{Hg})$ & $134.7(17.1)$ & $146.3(18.5)$ & $131.2(16.7)$ & $129.7(12.7)$ & $131.2(15.8)$ \\
\hline $\mathrm{DBP}(\mathrm{mm} \mathrm{Hg})$ & $83.8(10.3)$ & $91.4(12.1)$ & $80.0(11.2)$ & $81.3(7.9)$ & $80.9(10.4)$ \\
\hline BMI $\left(\mathrm{kg} / \mathrm{m}^{2}\right)$ & $29.4(3.6)$ & $33.2(5.3)$ & $31.3(5.1)$ & $32.4(5.6)$ & $31.6(5.3)$ \\
\hline Smokers & $17(31 \%)$ & - & $208(29 \%)$ & $45(12 \%)$ & $270(23 \%)$ \\
\hline Cholesterol & - & - & $5.5(1.1)$ & $5.2(1.2)$ & $5.4(1.1)$ \\
\hline Antihypertensive medication & $21(39 \%)$ & $27(82 \%)$ & $260(36 \%)$ & $193(49 \%)$ & $501(42 \%)$ \\
\hline Prior vascular events & $2(4 \%)$ & - & - & $222(57 \%)$ & $224(19 \%)$ \\
\hline Diabetes & - & $4(12 \%)$ & - & $63(16 \%)$ & $67(16 \%)$ \\
\hline
\end{tabular}

Data are summarised as mean (SD), median (25th-75th centile) or $\mathrm{N}(\%)$ as appropriate. Note: not all baseline characteristics were available for all studies.

AHI, apnoea-hypopnoea index; BMI, body mass index; DBP, diastolic blood pressure; ESS, Epworth Sleepiness Score; ODI, oxygen desaturation index; SBP, systolic blood pressure. 


\begin{tabular}{|c|c|c|c|c|c|c|c|c|c|}
\hline \multirow[b]{2}{*}{ Systolic Blood Pressure } & \multirow[t]{2}{*}{$\mathrm{N}$} & \multirow[t]{2}{*}{$\begin{array}{c}\text { Control } \\
\text { Mean change } \\
\text { (SD) (mmHg) }\end{array}$} & \multirow[t]{2}{*}{$\mathrm{N}$} & \multirow[t]{2}{*}{$\begin{array}{c}\text { CPAP } \\
\text { Mean change } \\
\text { (SD) (mmHg) }\end{array}$} & \multicolumn{3}{|c|}{$\begin{array}{l}\text { Treatment effect }(\mathrm{mmHg}) \\
\qquad(95 \% \mathrm{Cl})\end{array}$} & \multicolumn{2}{|r|}{$\begin{array}{c}\text { Weight } \\
(\%)\end{array}$} \\
\hline & & & & & & & & & \\
\hline Barbe et al. (2001) & 24 & $-5.4(10.4)$ & 29 & $-3.6(16.6)$ & & & & $2.4(-3.4,8.2)$ & 4.6 \\
\hline Robinson et al. (2006) & 14 & $-9.0(11.1)$ & 12 & $-1.3(19.8)$ & & & & $4.6(-6.4,15.4)$ & 1.3 \\
\hline Barbe et al. (2012) & 324 & $-1.5(15.4)$ & 319 & $-1.8(16.0)$ & & $\rightarrow$ & & $-0.1(-2.2,1.9)$ & 37.9 \\
\hline Craig et al. (2012) & 175 & $-0.3(8.3)$ & 177 & $1.5(8.1)$ & & - & & $1.7(0.1,3.4)$ & 56.2 \\
\hline Overall & 537 & & 537 & & & 7 & & $1.1(-0.2,2.3)$ & $p=0.086$ \\
\hline Cochran $Q p=0.47,1^{2}=0 \%$ & & & & & -5 & 0 & 10 & & \\
\hline Diastolic Blood Pressure & & & & & & & & & \\
\hline Barbe et al. (2001) & 24 & $-1.3(9.2)$ & 29 & $-4.9(9.8)$ & & 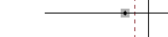 & & $-1.3(-5.9,3.2)$ & 3.5 \\
\hline Robinson et al. (2006) & 14 & $-5.4(9.7)$ & 12 & $-3.0(8.0)$ & & 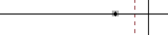 & & $-1.9(-8.7,4.9)$ & 1.6 \\
\hline Barbe et al. (2012) & 324 & $-0.5(11.5)$ & 318 & $-1.9(11.3)$ & & $\div$ & & $-1.2(-2.7,0.2)$ & 34.5 \\
\hline Craig et al. (2012) & 175 & $-0.0(5.1)$ & 177 & $-0.4(5.8)$ & & 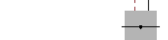 & & $-0.4(-1.5,0.7)$ & 60.5 \\
\hline & 537 & & 536 & & & i & & $-0.8(-1.6,0.1)$ & $p=0.083$ \\
\hline Overall & & & & & -10 & -5 & 5 & & \\
\hline
\end{tabular}

Figure 2 Effect of CPAP on systolic and diastolic blood pressures. Forest plots showing the effect of CPAP therapy relative to control on systolic (SBP) and diastolic (DBP) blood pressures in each study and overall. Also shown are the mean changes in SBP and DBP in each arm in each study.

minimally symptomatic OSA. In patients using CPAP $<4 \mathrm{~h} /$ night, SBP seemed to increase slightly relative to controls, whereas patients who used CPAP $>4 \mathrm{~h}$ per night seemed to benefit from a small decrease in DBP. It should be noted, however, that these latter findings are purely exploratory since the characteristics of patients using CPAP less than or more than $4 \mathrm{~h} /$ night could differ and thus introduce the possibility of confounding.

To date, there are four meta-analyses published on the impact of CPAP on BP in patients with OSAS. ${ }^{42-24}$ The meta-analysis by Haentjens et $a l^{4}$ included 572 patients from 12 RCTs in which ambulatory $24 \mathrm{~h} \mathrm{BP}$ was measured. The meta-analyses by Bazzano et $a l^{23}$ and Alajmi et $a l^{22}$ were restricted to RCTs with a treatment duration of at least 2 weeks. Haentjens et al found a modest average reduction of the mean $\mathrm{BP}$ of $1.7 \mathrm{~mm} \mathrm{Hg}$ with
CPAP, which is comparable to the findings of Bazzano et al $(-2.2 \mathrm{~mm} \mathrm{Hg})$ and Alajmi et al $(-1.5 \mathrm{~mm} \mathrm{Hg})$.

Our meta-analysis differs in some important aspects from previously published meta-analyses on the effect of CPAP on BP in patients with OSA. ${ }^{42-24}$ First, our meta-analysis is focused on trials that included patients with minimally symptomatic OSA only. Previously published meta-analyses have not included the most recent large studies on asymptomatic patients, ${ }^{9}{ }^{12}$ thereby making it difficult to draw definitive conclusions as to whether patients with minimally symptomatic OSA treated with CPAP benefit from a BP reduction. Secondly, our meta-analysis obtained data for individual patients, which allows analysis of different subgroups of patients, thus identifying those who are most likely to benefit from CPAP, and also allows adjustment for covariates, thus reducing potential bias and increasing power.

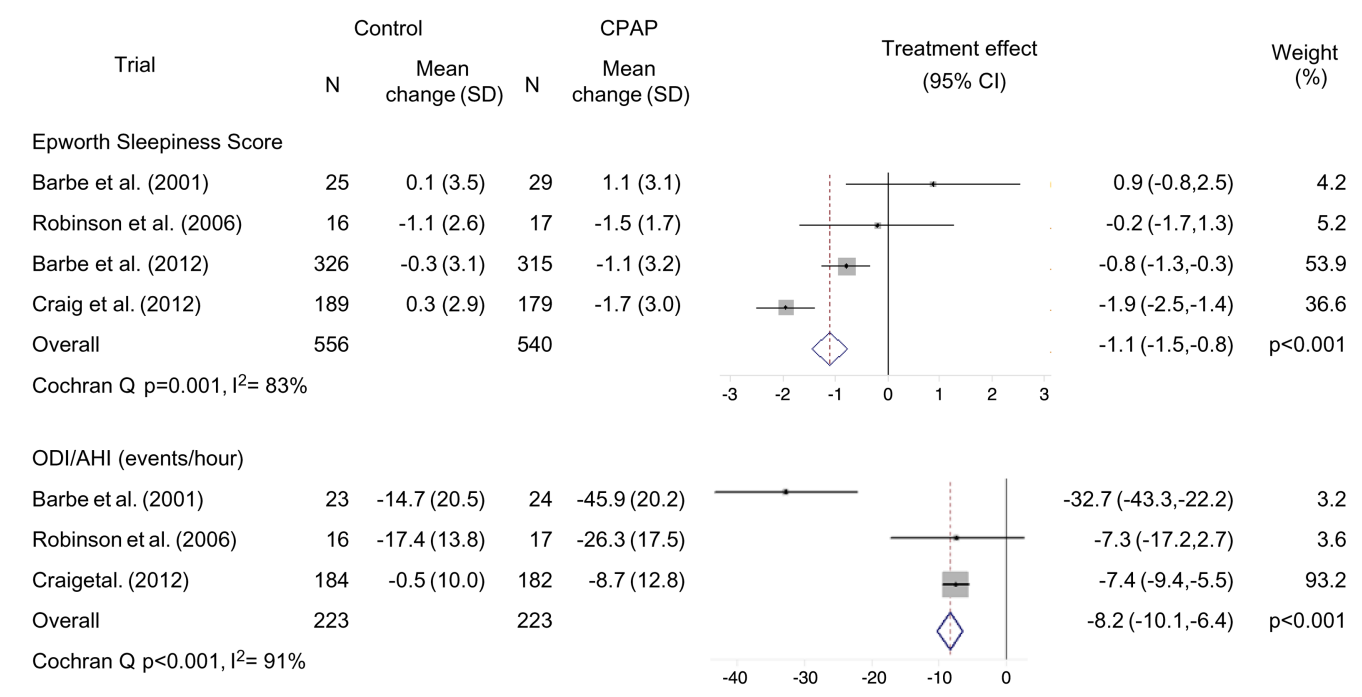

Figure 3 Effect of CPAP on subjective sleepiness and sleep apnoea severity. Forest plots showing the effect of CPAP therapy relative to control on Epworth Sleepiness Score (ESS) and oxygen desaturation index (ODI) or apnoea hypopnoea index (AHI) in each study and overall. Also shown are the mean changes in ESS and ODI/AHI in each arm in each study. Note: Barbé (2012) study not included in the analysis of ODI/AHI as follow-up data were unobtainable. 


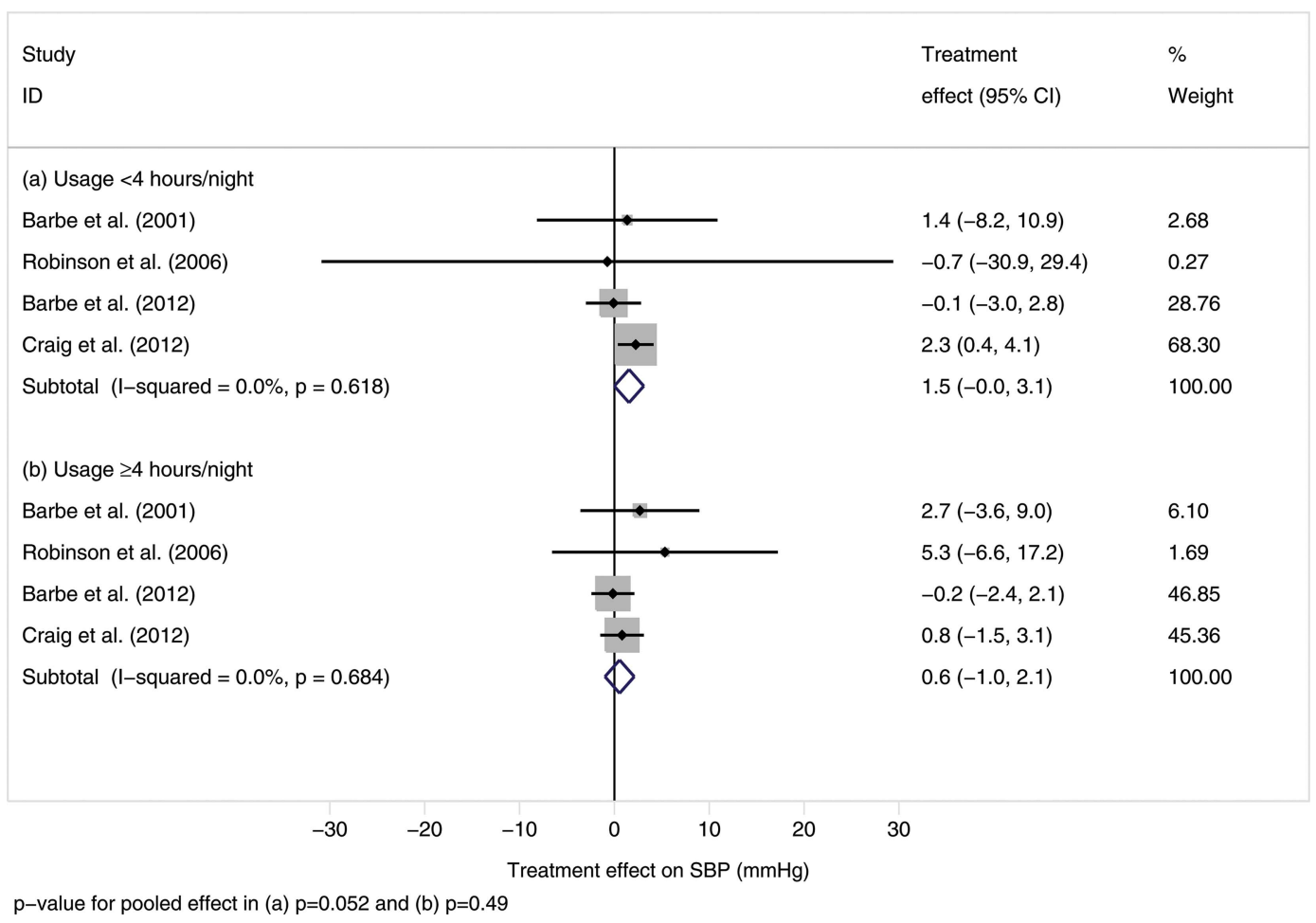

Figure 4 Forest plots showing the effect of less than and more than $4 \mathrm{~h} /$ night CPAP usage on systolic blood pressure (mm Hg) compared with control in each study and overall. Difference between pooled treatment effects: $p=0.41$.

In contrast to the findings of the previous meta-analyses, ${ }^{4} 22-24$ we did not find an overall beneficial effect of CPAP on BP in patients with minimally symptomatic OSA, although there is wide interindividual variation. Our findings imply that patients with minimally symptomatic OSA should generally not be treated with CPAP to reduce $\mathrm{BP}$ in order to improve cardiovascular risk. However, in clinical practice, a short trial of CPAP treatment may be indicated to identify those patients who do use CPAP for more than $4 \mathrm{~h} / \mathrm{night}$, and thus may benefit in terms of a BP reduction and improvement of endothelial

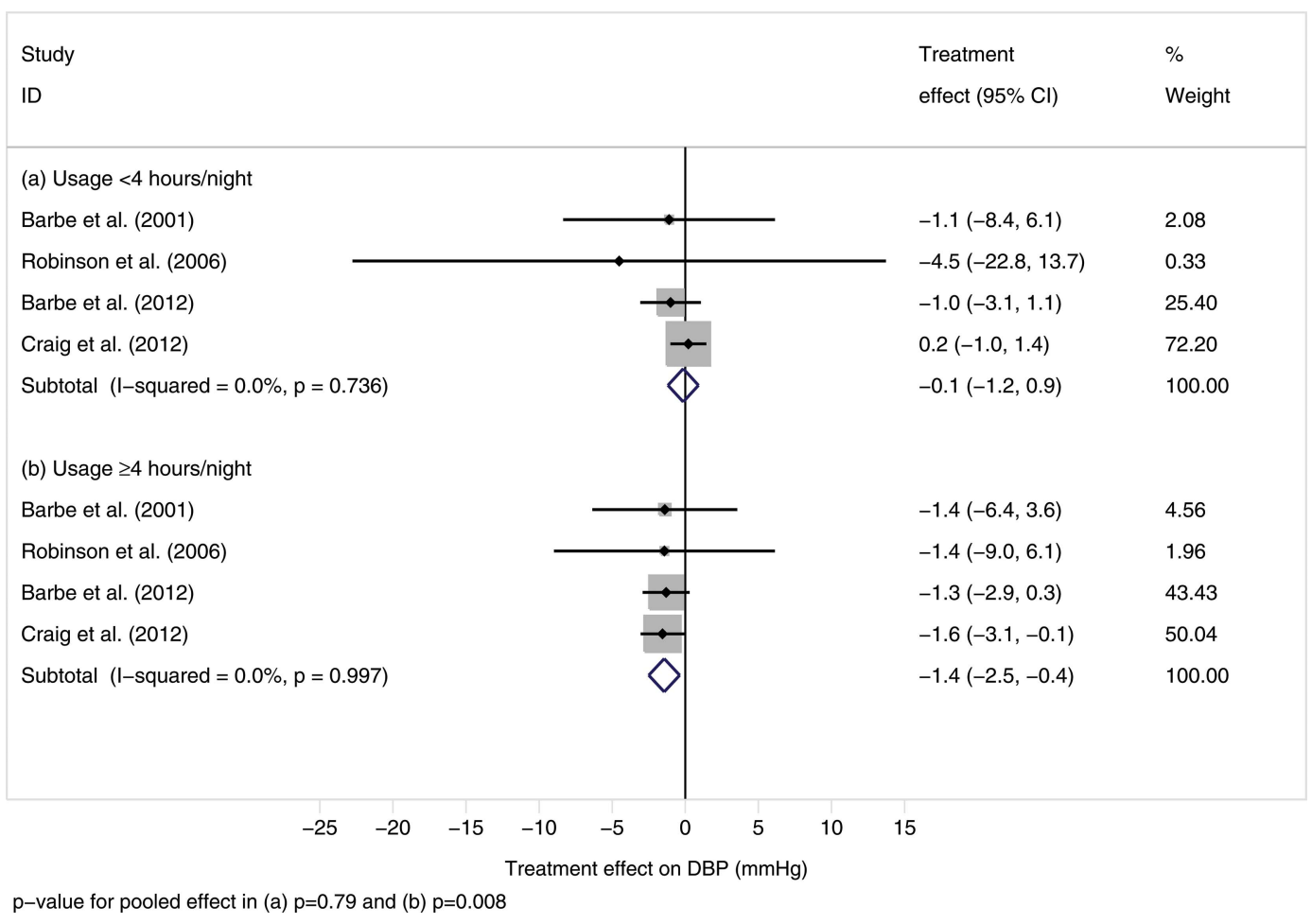

Figure 5 Forest plots showing the effect of less than and more than $4 \mathrm{~h} / \mathrm{night}$ CPAP usage on diastolic blood pressure (mm Hg) compared with control in each study and overall. Difference between pooled treatment effects: $p=0.062$. 
function. ${ }^{19}$ In this regard, even small effects on BP in the range of $1-2 \mathrm{~mm} \mathrm{Hg}$ may be of clinical significance as they are associated with reduced odds of cardiovascular and cerebrovascular events. ${ }^{25}$ At the same time, it must be stressed that, if used insufficiently, CPAP may potentially harm patients with minimally symptomatic OSA by slightly increasing SBP. This may be related to increased psychological stress from not being able to fully adapt to CPAP, or from difficulty in falling asleep for a prolonged period; both situations could be associated with increased sympathetic nervous system activation leading to the minimally increased office $\mathrm{BP}^{26} 27$ Thus, the absence of an effect on BP in previous studies of minimally symptomatic patients may have been generated by the generally lower compliance with CPAP in these studies. There is accumulating evidence that favourable adherence to CPAP (ie, $>4 \mathrm{~h} /$ night) is required to achieve beneficial effects on cardiovascular outcomes and this seems to be true not only for asymptomatic but also symptomatic patients with OSA. ${ }^{9} 19$ However, further research is needed to determine baseline predictors of optimal CPAP usage, thus allowing clinicians to better identify patients who are more likely to benefit from treatment.

In the current meta-analysis, there was no evidence that the treatment effect of CPAP on BP was dependent on the severity of OSA (as defined by ODI or AHI), which is in contrast to the report by Haentjens et al. ${ }^{4}$ Mean AHI in the two Barbé studies was higher than mean ODI in the other studies; however, this is due both to the Spanish studies using a higher inclusion threshold on $\mathrm{AHI}$ and that $\mathrm{AHI}$ values are usually higher than the equivalent ODI, especially when using $>4 \%$ dips in $\mathrm{SaO}_{2}$.

A possible limitation of the meta-analysis is that not all studies used the same follow-up length or the same treatment for the control arm. The two largest studies used standard of care and patients were followed up at a 6-month visit. By contrast, the two smaller studies used sham-CPAP and followed patients for a shorter period of time. However, since these two studies consisted of about $7 \%$ of the total number of patients only, they are unlikely to greatly influence the overall results of the meta-analysis.

Despite the studies in this meta-analysis looking at patients with apparently normal levels of daytime sleepiness and only minimal symptoms, there was an average reduction in ESS of about one point in patients using CPAP relative to control, with

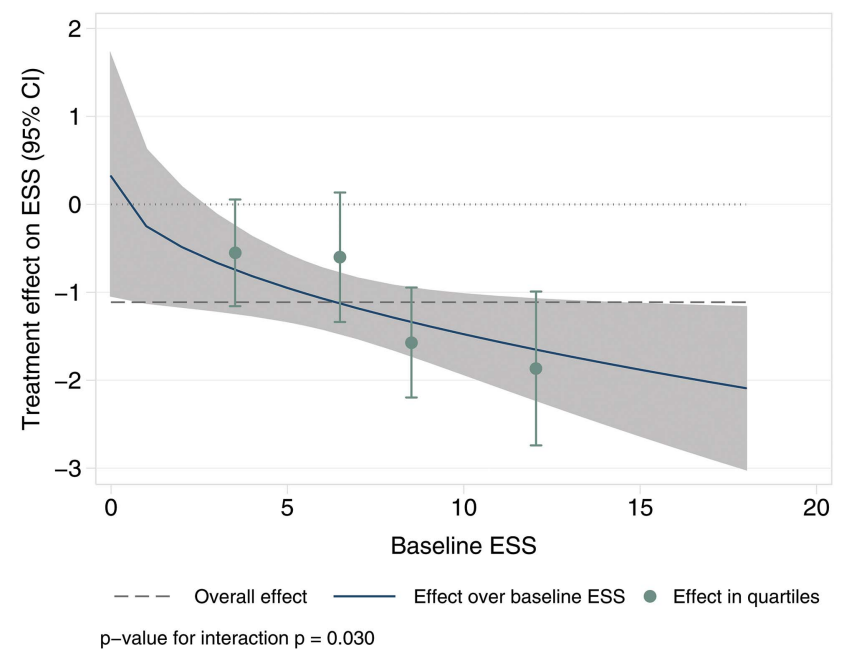

Figure 6 Effect of CPAP on change in Epworth Sleepiness Score (ESS) compared with control over the full range and in quartiles of observed baseline ESS.

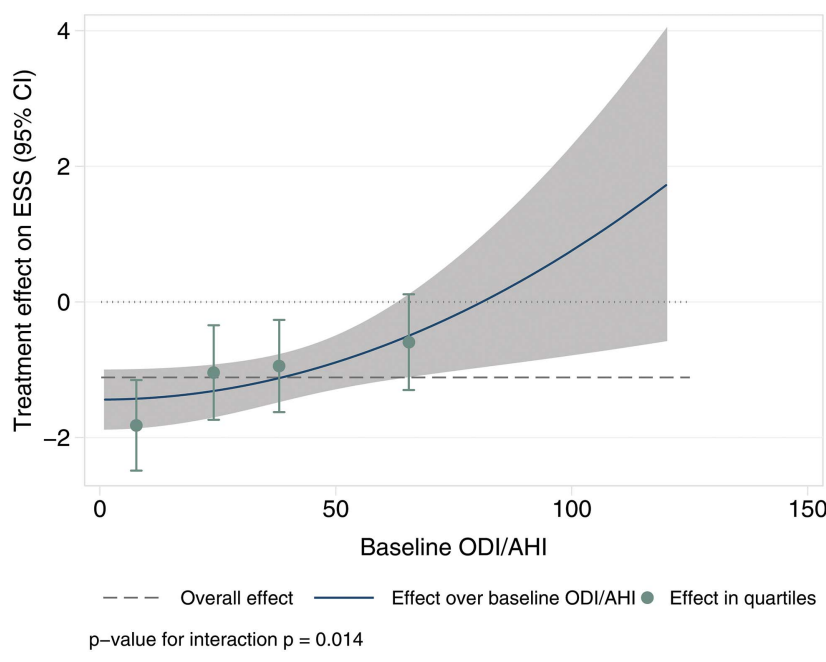

Figure 7 Effect of CPAP on change in Epworth Sleepiness Score compared with control over the full range and in quartiles of observed baseline oxygen desaturation index or apnoea hypopnoea index.

considerable variability across baseline ESS. For instance, this improvement was greater in those with an initially higher ESS, which would be expected (figure 6). There was also a dependence on initial OSA severity (figure 7) with more severe patients benefitting less from treatment. In clinical practice, this means that it is not possible to confidently predict who is going to benefit most from CPAP therapy in terms of sleepiness reduction, again suggesting that a trial of CPAP therapy is required to establish likely benefit.

Finally, in this study, we have used a novel method for performing a meta-analysis of treatment interactions with continuous covariates, based on a method introduced by Sauerbrei and Royston for observational studies. ${ }^{20}$ By using the full information in the data, this method is more powerful than the common approach of examining the pooled treatment effect in subgroups of a continuous covariate, and more flexible than assuming a linear relationship between treatment effect and the covariate. By showing the interaction in more detail, more precise conclusions can be drawn about which patients may benefit from treatment. We therefore strongly recommend its use in future meta-analyses. Stata software is available from the authors upon request.

In conclusion, although CPAP treatment reduces OSA severity and sleepiness, it seems not to have a beneficial effect on BP in patients with minimally symptomatic OSA, except in those patients who used CPAP for $>4 \mathrm{~h} /$ night.

Acknowledgements The authors would like to thank Patrick Royston (MRC Clinical Trials Unit) for his help in developing the methods for performing the meta-analysis of treatment interactions with continuous covariates. We would also like to thank Claire Vale (MRC Clinical Trials Unit) for her guidance on performing the literature search and for comments on an earlier draft of this manuscript.

Contributors DJB was responsible for the search of trials, data extraction, data analysis, interpretation of results and drafting the manuscript. JRS and MK were responsible for the study conception, collection of trial data, data extraction, interpretation of results and drafting the manuscript. FB was responsible for data extraction, interpretation of results and drafting of the manuscript. DJB had full access to all of the data in the study and can take responsibility for the integrity of the data and the accuracy of the data analysis.

Competing interests None.

Provenance and peer review Not commissioned; externally peer reviewed.

Open Access This is an Open Access article distributed in accordance with the Creative Commons Attribution Non Commercial (CC BY-NC 3.0) license, which permits others to distribute, remix, adapt, build upon this work non-commercially, 
and license their derivative works on different terms, provided the original work is properly cited and the use is non-commercial. See: http://creativecommons.org/ licenses/by-nc/3.0/

\section{REFERENCES}

1 Young T, Peppard PE, Gottlieb DJ. Epidemiology of obstructive sleep apnea: a population health perspective. Am J Respir Crit Care Med 2002;165:1217-39.

2 Kohler M, Stradling JR. Mechanisms of vascular damage in obstructive sleep apnea. Nat Rev Cardiol 2010;7:677-85.

3 Becker HF, Jerrentrup A, Ploch $T$, et al. Effect of nasal continuous positive airway pressure treatment on blood pressure in patients with obstructive sleep apnea. Circulation 2003;107:68-73.

4 Haentjens P, Van Meerhaeghe A, Moscariello A, et al. The impact of continuous positive airway pressure on blood pressure in patients with obstructive sleep apnea syndrome: evidence from a meta-analysis of placebo-controlled randomized trials. Arch Intern Med 2007;167:757-64.

5 Pepperell JC, Ramdassingh-Dow S, Crosthwaite N, et al. Ambulatory blood pressure after therapeutic and subtherapeutic nasal continuous positive airway pressure for obstructive sleep apnoea: a randomised parallel trial. Lancet 2002;359:204-10.

6 Kohler M, Stoewhas AC, Ayers L, et al. Effects of continuous positive airway pressure therapy withdrawal in patients with obstructive sleep apnea: a randomized controlled trial. Am J Respir Crit Care Med 2011;184:1192-9.

7 Lozano L, Tovar JL, Sampol G, et al. Continuous positive airway pressure treatment in sleep apnea patients with resistant hypertension: a randomized, controlled trial. J Hypertens 2010;28:2161-8.

8 Pedrosa RP, Drager LF, LK GdP, et al. Effects of obstructive sleep apnea treatment on blood pressure in patients with resistant hypertension: a randomized trial. Chest 2013;144:1487-94.

9 Barbé F, Duran-Cantolla J, Sanchez-de-la-Torre M, et al. Effect of continuous positive airway pressure on the incidence of hypertension and cardiovascular events in nonsleepy patients with obstructive sleep apnea: a randomized controlled trial. JAMA 2012;307:2161-8.

10 Barbé F, Mayoralas LR, Duran J, et al. Treatment with continuous positive airway pressure is not effective in patients with sleep apnea but no daytime sleepiness. a randomized, controlled trial. Ann Intern Med 2001;134:1015-23.

11 Comondore VR, Cheema R, Fox J, et al. The impact of CPAP on cardiovascular biomarkers in minimally symptomatic patients with obstructive sleep apnea: a pilot feasibility randomized crossover trial. Lung 2009;187:17-22.

12 Craig SE, Kohler M, Nicoll D, et al. Continuous positive airway pressure improves sleepiness but not calculated vascular risk in patients with minimally symptomatic obstructive sleep apnoea: the MOSAIC randomised controlled trial. Thorax 2012:67:1090-6.
13 Robinson GV, Smith DM, Langford BA, et al. Continuous positive airway pressure does not reduce blood pressure in nonsleepy hypertensive OSA patients. Eur Respir J 2006;27:1229-35

14 Royston P, Sauerbrei W. Multivariable model-building: a pragmatic approach to regression analysis based on fractional polynomials for modelling continuous variables. John Wiley, 2008

15 Lefebvre C, Manheimer E, Glanville J. Chapter 6: Searching for studies. In: Higgins JPT, Green S, eds. Cochrane handbook for systematic reviews of interventions version 5.1.0 (updated March 2011). The Cochrane Collaboration, 2011. www. cochrane-handbook.org

16 Higgins JP, Thompson SG. Quantifying heterogeneity in a meta-analysis. Stat Med 2002:21:1539-58.

17 Higgins JP, Thompson SG, Deeks JJ, et al. Measuring inconsistency in meta-analyses. BMJ 2003;327:557-60.

18 Higgins J, Thompson S, Deeks J, et al. Statistical heterogeneity in systematic reviews of clinical trials: a critical appraisal of guidelines and practice. J Health Serv Res Policy 2002;7:51-61.

19 Kohler M, Craig S, Pepperell JC, et al. CPAP improves endothelial function in minimally symptomatic OSA patients: results from a subset study of the MOSAIC trial. Chest 2013;144:896-902.

20 Sauerbrei W, Royston P. A new strategy for meta-analysis of continuous covariates in observational studies. Stat Med 2011:30:3341-60.

21 Jackson D, Riley R, White IR. Multivariate meta-analysis: Potential and promise. Stat Med 2011:30:2481-98.

22 Alajmi M, Mulgrew AT, Fox J, et al. Impact of continuous positive airway pressure therapy on blood pressure in patients with obstructive sleep apnea hypopnea: a meta-analysis of randomized controlled trials. Lung 2007;185:67-72.

23 Bazzano LA, Khan Z, Reynolds K, et al. Effect of nocturnal nasal continuous positive airway pressure on blood pressure in obstructive sleep apnea. Hypertension 2007;50:417-23

24 Mo L, He QY. [Effect of long-term continuous positive airway pressure ventilation on blood pressure in patients with obstructive sleep apnea hypopnea syndrome: a meta-analysis of clinical trials]. Zhonghua yi xue za zhi 2007;87: 1177-80.

25 Turnbull F. Effects of different blood-pressure-lowering regimens on major cardiovascular events: results of prospectively-designed overviews of randomised trials. Lancet 2003:362:1527-35.

26 Ogedegbe G, Pickering TG, Clemow L, et al. The misdiagnosis of hypertension: the role of patient anxiety. Arch Intern Med 2008;168:2459-65.

27 Tobaldini E, Cogliati C, Fiorelli EM, et al. One night on-call: Sleep deprivation affects cardiac autonomic control and inflammation in physicians. Eur J Intern Med 2013:24:664-70. 